\title{
Reduction of the Electrode Overpotential of the Oxygen Evolution Reaction by Electrode Surface Modification
}

\author{
Cian-Tong Lu, ${ }^{1}$ Yen-Wen Chiu, ${ }^{2}$ Mei-Jing Li, ${ }^{1}$ Kan-Lin Hsueh, ${ }^{1}$ and Ju-Shei Hung ${ }^{2}$ \\ ${ }^{1}$ Department of Energy Engineering, National United University, Miaoli, Taiwan \\ ${ }^{2}$ Department of Chemical Engineering, National United University, Miaoli, Taiwan \\ Correspondence should be addressed to Kan-Lin Hsueh; kanlinhsueh@hotmail.com and Ju-Shei Hung; hungjs@nuu.edu.tw
}

Received 24 October 2016; Revised 15 January 2017; Accepted 16 March 2017; Published 28 June 2017

Academic Editor: Ritesh Sachan

Copyright (c) 2017 Cian-Tong Lu et al. This is an open access article distributed under the Creative Commons Attribution License, which permits unrestricted use, distribution, and reproduction in any medium, provided the original work is properly cited.

\begin{abstract}
Metal-air batteries exhibit high potential for grid-scale energy storage because of their high theoretical energy density, their abundance in the earth's crust, and their low cost. In these batteries, the oxygen evolution reaction (OER) occurs on the air electrode during charging. This study proposes a method for improving the OER electrode performance. The method involves sequentially depositing a Ni underlayer, Sn whiskers, and a Ni protection layer on the metal mesh. Small and uniform gas bubbles form on the $\mathrm{Ni} / \mathrm{Sn} / \mathrm{Ni}$ mesh, leading to low overpotential and a decrease in the overall resistance of the OER electrode. The results of a simulated life cycle test indicate that the $\mathrm{Ni} / \mathrm{Sn} / \mathrm{Ni}$ mesh has a life cycle longer than 1,300 cycles when it is used as the OER electrode in $6 \mathrm{M}$ $\mathrm{KOH}$.
\end{abstract}

\section{Introduction}

To overcome possible energy shortages and to reduce the emissions of greenhouse gases, traditional fossil fuel has been gradually replaced by clean and sustainable energy sources such as photovoltaic and wind power. The electricity generated from these renewable energy sources is intermittent, and the supply of a large amount of electricity to a power grid may degrade the grid power quality and destabilize the grid. Electric energy storage technology is crucial for harnessing photovoltaic and wind energy. Because of their high energy density, low environmental constraints, and low ecological impacts, batteries are more attractive than pumped hydroelectric storage for electric energy storage. In addition to commercially available batteries, such as lead acid and lithium-ion batteries, the metal-air battery is a potential candidate for grid-scale electric energy storage [1]. Metal-air batteries currently under development are lithium-air, sodiumair, aluminum-air, magnesium-air, and zinc-air batteries. They are promising for grid energy storage and future generations of electric vehicles, and they have many advantages over traditional batteries, such as high energy density and low cost; for instance, the energy density of the lithium-air battery can reach $0.5-0.7 \mathrm{kWh} \mathrm{kg}^{-1}$ [2]. This is much higher than the energy density of lead acid battery $0.02-0.05 \mathrm{kWh} \mathrm{kg}^{-1}$.

There are several types of metal-air batteries. On the basis of the electrolyte used, they can be categorized into aqueous electrolytic, aprotic-nonaqueous electrolytic, mixed (aproticaqueous), and solid-state types [3]. At present, the only commercialized metal-air battery is the zinc-air battery, which is primarily used in hearing aids. This battery involves using an aqueous alkaline electrolyte, and it cannot be recharged because of the occurrence of water electrolysis on the zinc electrode during charging. On the air electrode, the electrochemical reactions occurring during charging and discharging differ.

The electrochemical reactions occurring on the air electrode during charging and discharging are the oxygen evolution reaction (OER) and oxygen reduction reaction (ORR), respectively. During charging, the $\mathrm{OH}^{-}$ions are oxidized, and oxygen bubbles form on the air electrode as expressed in (1). During discharging, oxygen diffuses into the air electrode and is reduced, leading to the generation of $\mathrm{OH}^{-}$ions.

$$
4 \mathrm{OH}^{-} \stackrel{\text { cat. }}{\longleftrightarrow} \mathrm{O}_{2}+2 \mathrm{H}_{2} \mathrm{O}+4 \mathrm{e}^{-}
$$




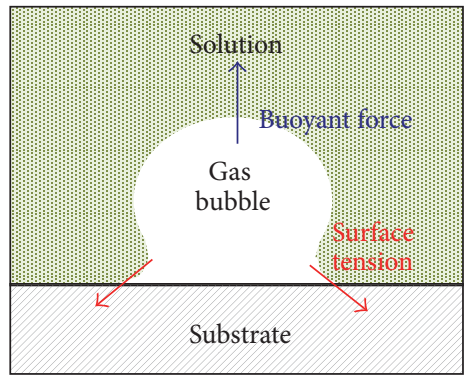

(a)

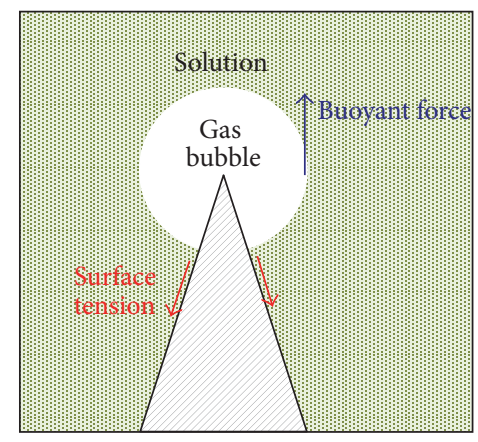

(b)

Figure 1: Schematic representation of a gas bubble attached to a (a) flat surface and (b) conical surface.

In general, three air electrode configurations have been used for the metal-air battery [4]: (a) a two-electrode configuration, one each for the OER and ORR; (b) a single electrode with a catalyst layer, which is a bifunctional catalyst participating in both the OER and ORR; and (c) a single electrode with two catalyst layers, one each for the OER and ORR. The characteristics of the OER differ from those of the ORR. The OER electrode should be hydrophilic because it should not only be easily wetted by water but also expel gas bubbles easily. The ORR electrode should be hydrophobic to prevent flooding and facilitate oxygen diffusion. The two-electrode configuration of the air electrode is appropriate because of the different requirements of the OER and ORR. The present study focused on the OER electrode of the zinc-air battery. There are two approaches to improving the OER electrode performance during charging: increase the electrode reaction rate by using either an active catalyst or a high-surface-area electrode and reduce the internal resistance of the electrode by rapidly removing the gas bubbles.

Catalysts for the OER have been extensively studied, mainly for hydrogen production from water electrolysis. Tilak et al. [5] summarized the OER and hydrogen evolution reaction kinetics from the literature preceding 1980 . The voltage required for water electrolysis at a low current density of $2 \mathrm{~mA} \mathrm{~cm}^{-2}$ is the lowest when the transition elements $\mathrm{Ni}, \mathrm{Pd}$, and $\mathrm{Pt}$ and nearby elements of the periodic table (Fe, Rh, and Ir) are used as the catalyst. The OER Tafel slope for a single element (such as Pt, Ir, Ru, Os, Ni, and Co), a binary element (Ni-Ir, Ni-Ru, Ni-W, and $\mathrm{Ni}-\mathrm{Ti})$, and oxides $\left(\mathrm{TiO}_{2}-\mathrm{Pt} /\right.$ $\mathrm{Co} / \mathrm{Ru}$ oxides) in $30 \% \mathrm{KOH}$ at $80^{\circ} \mathrm{C}$ is approximately 60 or $120 \mathrm{mV}$ decade ${ }^{-1}$. The exchange current densities of these catalysts range from $10^{-9} \mathrm{~A} \mathrm{~cm}^{-2}$ to $10^{-5} \mathrm{~A} \mathrm{~cm}^{-2}$. The recent literature shows that current research on the metal-air battery is focused on the development of new catalysts such as $\mathrm{N}$ doped, $\mathrm{MnO}_{x}$, and $\mathrm{Fe} / \mathrm{Co} / \mathrm{Ni}$ catalysts for increasing battery efficiency [6-11].

When the removal of $\mathrm{O}_{2}$ bubbles is not sufficiently rapid, the electrode surface becomes covered by the bubbles, which not only occupy electrode reaction sites but also block the ion conduction path. The gas bubbles increase the electrolyte resistance, as expressed in the Bruggeman equation:

$$
R_{b}=R_{e}(1-\varepsilon)^{-3 / 2}
$$

where $R_{b}$ and $R_{e}$ denote the electrolyte resistance in the presence and absence of gas bubbles, respectively, and $\varepsilon$ is the volumetric fraction of gas bubbles. Additionally, the bubbles increase the activation overpotential and decrease the energy storage efficiency of the battery $[12,13]$. The size of the gas bubbles can be reduced or the bubbles can be removed using a hydrophobic surface [14] or by applying an external magnetic field [15]. Furthermore, the bubbles can be quickly removed by varying the surface morphology. The force balance between buoyancy and surface tension determines the size of a gas bubble. As illustrated in Figure 1, the buoyancy $\left(f_{b}\right)$ that lifts a gas bubble is obtained using ( 3 ), and it is proportional to the difference between the density of water $\left(\rho_{\text {water }}\right)$ and the density of the gas bubble $\left(\rho_{\text {bubble }}\right)$.

$$
f_{b}=g V_{\text {bubble }}\left(\rho_{\text {water }}-\rho_{\text {bubble }}\right) \text {, }
$$

where $V_{\text {bubble }}$ is the volume of the gas bubble and $g$ is the gravitational constant. The force holding the gas bubble $\left(f_{s}\right)$ depends on the surface tension $(\gamma)$ and contact angle $(\theta)$.

$$
f_{s}=2 \pi r_{c} \gamma \sin \theta
$$

where $r_{c}$ is the radius of the bubble in contact with the OER electrode substrate. The volume of the gas bubble can be calculated by balancing the buoyancy and the surface tension:

$$
V_{\text {bubble }}=\frac{2 \pi r_{c} \gamma \sin \theta}{g\left(\rho_{\text {water }}-\rho_{\text {bubble }}\right)}
$$

As shown in Figure 1, the radius of a gas bubble attached to a flat surface is considerably larger than that of a gas bubble attached to a conical or whisker surface. The whisker surface reduces the volume of the gas bubble. The size of the gas bubble can be reduced by decreasing the surface tension or contact angle. However, bubble size reduction is not the focus of the present study.

We deposited a whisker-like surface on a stainless steel (SS) mesh for use as the OER electrode. The whisker structure caused gas bubbles to leave the electrode surface and to have a smaller size than that of gas bubbles on a flat surface. Several studies have fabricated 3D electrode structures (i.e., dendrites) by using electroplating, to increase the active surface area and capacitor capacity [16-20]. The gas bubbles that formed at the tip of the dendrites collapsed to form a 
large bubble before escaping from the electrode. The shape of whiskers is different from that of dendrites. Whereas dendrites have a fern-like or snowflake-like structure, whiskers are thin hair-like protrusions. Bubbles that form on whiskers are separate from each other.

The deposition of $\mathrm{Sn}$ is common in the electronic industry for purposes such as soldering. The deposition of pure Sn tends to form whisker deposits [21], which cause problems; therefore, many attempts have been made to eliminate whisker growth during the electrochemical deposition of Sn [22]. In the current study, because a whisker structure was desirable, we grew whiskers in a controlled manner to obtain evenly distributed short whiskers on the deposition surface. A three-layer electrode structure $(\mathrm{Ni} / \mathrm{Sn} / \mathrm{Ni})$ was obtained on the SS mesh by sequentially depositing layers through a metal deposition technique. Various surface morphologies were obtained by varying the deposition conditions. The properties of the OER were determined and the polarization curve was measured.

Our previous work [23] indicated that whisker structure on stainless steel mesh reduced the OER overpotential and produced small uniform oxygen gas bubbles. The OER electrode had a stable potential during charging over 428 cycles. However, due to long and scattering whiskers, the needle-like structure on the electrode was very easily damaged. Present work is intended to explore the deposition condition that produces durable whiskers and to analyze the factors that reduce OER overpotential, such as Tafel slope and internal resistance of the OER polarization curve.

\section{Experiment}

2.1. Substrate Pretreatment. In all the experiments, the substrate was a $304 \mathrm{SS}$ mesh $(3.3 \mathrm{~cm} \times 3.3 \mathrm{~cm}$; Shang Kai Steel Co.) degreased with acetone. The surface oxide on the mesh was removed using an etchant consisting of $2 \mathrm{M} \mathrm{HCl}$ (Chyng Yang Trading Co., reagent grade) and $1 \mathrm{M} \mathrm{H}_{2} \mathrm{O}_{2}$ (ECHO Chemical Co., 35\%). The etched sample was rinsed with deionized water.

2.2. Electrodeposition. After the pretreatment of the SS mesh, it was sequentially deposited with three layers of metals: $\mathrm{Ni}$, $\mathrm{Sn}$, and Ni. First, a Ni underlayer was coated on the SS mesh for increased adhesion. A Sn whisker structure was then deposited on the Ni surface. Finally, a protective layer of $\mathrm{Ni}$ was deposited on the Sn surface. Both the Ni underlayer and protective layer were deposited from a nickel sulfate bath at $40^{\circ} \mathrm{C}$. The ingredients of the nickel sulfate bath were purchased from Wetchem Pro Chemical and Materials Corporation (bath: BNI 100). The whisker structure was obtained by depositing $\mathrm{Sn}$ from a Sn bath containing $0.5 \mathrm{M} \mathrm{SnCl}$ (Wako Pure Chemical Industries, Ltd., reagent grade) and $2 \mathrm{M} \mathrm{HCl}$ at $30^{\circ} \mathrm{C}$. A protective layer of nickel was then deposited on the Sn surface from the nickel sulfate bath. The electrodeposition current and electrodeposition duration were controlled using a power supply (Jiehan Co., 2030 Periodic Pulse Power Supply).

The mesh was fixed in the middle of the beaker by using an acryl fixture, which around the mesh edge blocked the deposition current and reduced excessive whisker growth. Two counter plates were placed on both sides of the mesh to ensure a uniform electrodeposition current. During the Ni electrodeposition, the counter electrode comprised nickel nuggets in a steel basket, and during the Sn electrodeposition a Sn counter electrode was used. The plating cell was immersed in a temperature-controlled water bath.

2.3. Characterization of Deposits. The morphologies of the Ni and Sn layers deposited on the SS mesh were observed using scanning electron microscopy (SEM, JEOL Semiconductors, Ltd., JSM-6700). Cyclic voltammetry (CV) and linear scanning voltammetry (LSV) measurements were performed at ambient temperature by using $\mathrm{AgCl} / \mathrm{Ag}$ as the reference electrode and a Pt wire as the counter electrode. The surface area of the deposited layers was measured using CV scanning at different scan rates in $0.5 \mathrm{M} \mathrm{H}_{2} \mathrm{SO}_{4}$ (Scharlau, reagent grade). The electrochemical active surface area was estimated according to the double-layer charging current determined from the $\mathrm{CV}$ data in the potential region $(-0.34$ to $-0.25 \mathrm{~V}$ versus $\mathrm{AgCl} / \mathrm{Ag}$ ). The polarization curves of the OER in 6.0 $\mathrm{M} \mathrm{KOH}$ solution were measured using LSV at a scanning rate of $0.24 \mathrm{mV} \mathrm{s}^{-1}$.

A life cycle test was conducted using the $\mathrm{Ni} / \mathrm{Sn} / \mathrm{Ni}$ mesh $(3.3 \mathrm{~cm} \times 3.3 \mathrm{~cm})$ as the OER electrode. To simulate the air electrode during charging, the life cycle of the $\mathrm{Ni} / \mathrm{Sn} / \mathrm{Ni}$ mesh was measured using a single cell. An electrode used in protonexchange membrane fuel cells (Genius Toy Taiwan Co., Ltd.) was used as the ORR electrode $(2.5 \mathrm{~cm} \times 3.7 \mathrm{~cm})$ during discharging. A Pt wire was used as the metal electrode. A switching circuit was used to switch the current to the OER electrode (during charging) and to the ORR electrode (during discharging). A constant current density of $0.1 \mathrm{~mA}$ $\mathrm{cm}^{-2}$ was applied for both charging and discharging. A $6 \mathrm{M}$ $\mathrm{KOH}$ solution was used as the electrolyte. Autolab (Metrohm, AUT85126) was used for all the electrochemical measurements. The Ni/Sn/Ni mesh and ORR electrode were positioned parallel to each other, and a $\mathrm{Pt}$ wire was used as the counter electrode. A relay circuit was used to control the current flow during charging and discharging. During charging, the current flowed from the $\mathrm{Ni} / \mathrm{Sn} / \mathrm{Ni}$ mesh to the Pt electrode; during discharging, the current flowed from the $\mathrm{Pt}$ electrode to the ORR electrode. A timer was used to control the relay, which switched the current during charging and discharging. In the life cycle test, the duration of each cycle was $30 \mathrm{~min}$.

\section{Result}

3.1. Electrodeposition of Nickel Underlayer. After the SS mesh was cleaned with acetone and immersed in the etching solution for $5 \mathrm{~min}$, the surface of the mesh was electrodeposited with a Ni underlayer for enhancing the adhesion of subsequent layers and protecting the mesh from corrosion in alkaline solutions. Ni has higher corrosion resistance than SS does. A constant current density of $200 \mathrm{~mA} \mathrm{~cm}^{-2}$ was applied for the deposition of the underlayer.

To ensure the complete coverage of the mesh surface by the $\mathrm{Ni}$ underlayer, the open circuit potential (OCP) of 


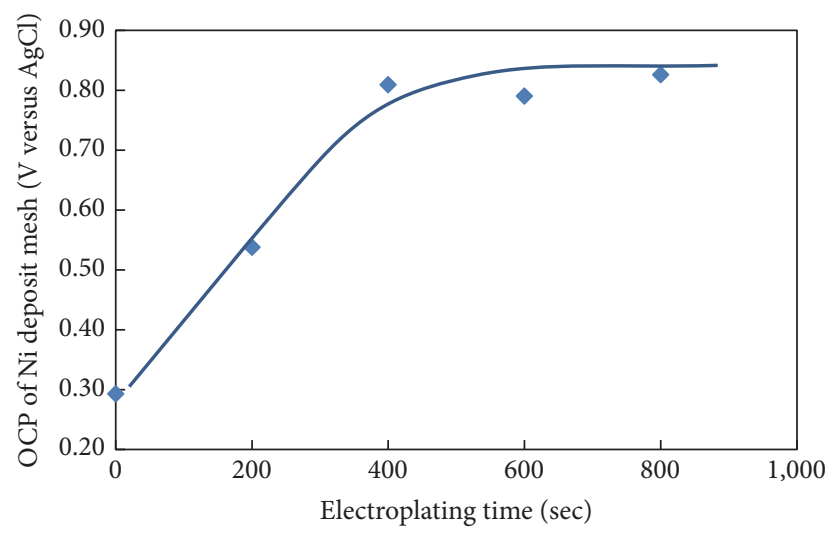

Figure 2: OCP of the Ni-deposited mesh in $6.0 \mathrm{M} \mathrm{KOH}$ solution plotted as a function of electrodeposition time. The etching solution used was a mixture of $1 \mathrm{M} \mathrm{H}_{2} \mathrm{O}_{2}$ and $2 \mathrm{M} \mathrm{HCl}$, and the etching time was $5 \mathrm{~min}$. Ni was deposited at a current density of $0.2 \mathrm{~A} \mathrm{~cm}^{-2}$.

the Ni-deposited mesh was measured in $6 \mathrm{M} \mathrm{KOH}$ solution. The OCP is plotted as a function of the electrodeposition time in Figure 2. Initially, the OCP was $0.3 \mathrm{~V}$, and its value increased with an electrodeposition time of up to $400 \mathrm{~s}$. The OCP saturated at an electrodeposition time of $400 \mathrm{~s}$.

The theoretical OCP of a metal in $6 \mathrm{M} \mathrm{KOH}$ can be explained on the basis of "theory of mixing potential." When a metal mesh is immersed in an alkaline solution, a galvanic reaction occurs. The metal oxidation reaction and water electrolysis are taking place on the Fe-based mesh surface. Because the $\mathrm{Ni}$ deposition preceded, the Fe-based mesh surface was gradually covered by a Ni layer. The equilibrium potential (OCP) of the mesh shifted from that of Fe to the equilibrium potential of Ni. The result depicted in Figure 2 suggests that the mesh surface was completely covered by a $\mathrm{Ni}$ base layer after $400 \mathrm{~s}$. The base layer was equivalent to 80 $\mathrm{C} \mathrm{cm}^{-2}$ of charge or a $27 \mu \mathrm{m}$ thick Ni layer. To ensure complete coverage by the Ni layer, a deposition time of $480 \mathrm{~s}$ was applied at a deposition current of $2 \mathrm{~A}\left(200 \mathrm{~mA} \mathrm{~cm}^{-2}\right)$.

\subsection{Electrodeposition of Sn Whisker and Ni Protective Layer.} Sn has a unique property: it easily forms a whisker structure during deposition. This property was applied to obtain a whisker structure on the mesh. This structure reduced the contact area between the mesh and bubbles. To protect the structure of $\mathrm{Sn}$ whiskers, a protective layer of $\mathrm{Ni}$ was deposited on the $\mathrm{Ni} / \mathrm{Sn}$ mesh at $200 \mathrm{~mA} \mathrm{~cm}^{-2}$ for $960 \mathrm{~s}$. Figure 3 shows the polarization curve of the $\mathrm{Ni} / \mathrm{Sn} / \mathrm{Ni}$ mesh in $6 \mathrm{M} \mathrm{KOH}$ solution. An anodic current was passed through the $\mathrm{Ni} / \mathrm{Sn} / \mathrm{Ni}$ mesh. This test condition simulated the condition for charging the metal-air battery while the OER was occurring on the air electrode. The $\mathrm{Ni} / \mathrm{Sn} / \mathrm{Ni}$ mesh was obtained by depositing $\mathrm{Sn}$ on the Ni-deposited mesh at different current densities and for various deposition durations $\left(50 \mathrm{~mA} \mathrm{~cm}^{-2}\right.$ for $500 \mathrm{~s}, 100 \mathrm{~mA} \mathrm{~cm}^{-2}$ for $250 \mathrm{~s}, 150 \mathrm{~mA} \mathrm{~cm}^{-2}$ for $166 \mathrm{~s}$, $250 \mathrm{~mA} \mathrm{~cm}^{-2}$ for $100 \mathrm{~s}$, and $300 \mathrm{~mA} \mathrm{~cm}^{-2}$ for $83 \mathrm{~s}$ ). The total charge of the $\mathrm{Ni} / \mathrm{Sn} / \mathrm{Ni}$ meshes was maintained at $25^{\circ} \mathrm{C}$. As shown in Figure 3, an increase in the electrodeposition current density reduced the OER potential.

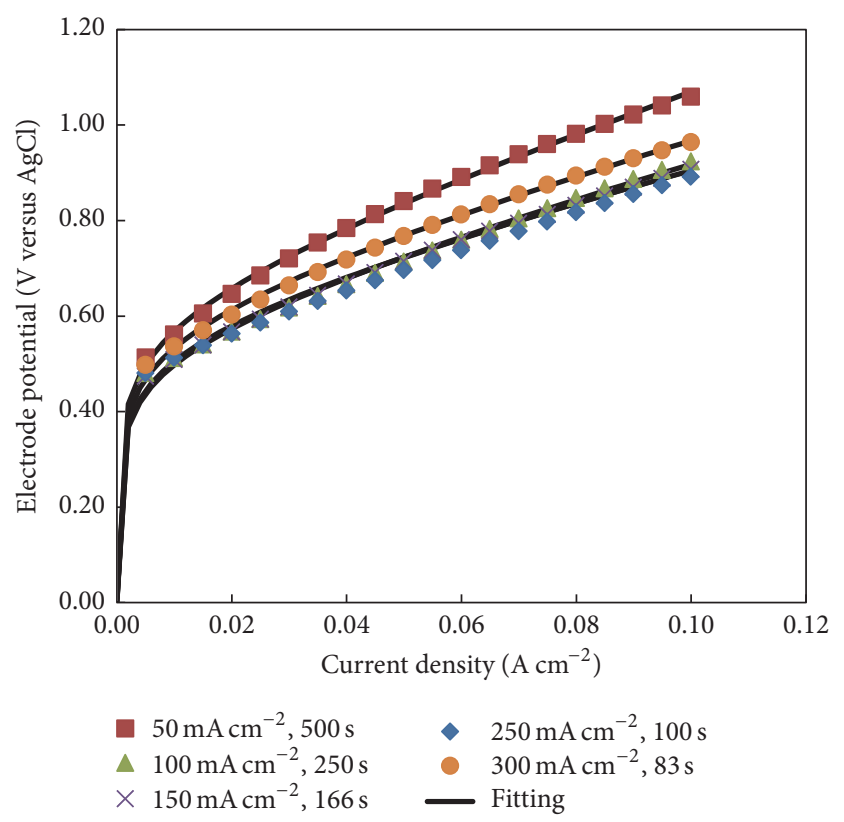

FIGure 3: Polarization curves of Ni/Sn-deposited meshes in $6.0 \mathrm{M}$ $\mathrm{KOH}$. The meshes were obtained at different Sn deposition current densities and for different deposition times.

3.3. SEM Images. Figures $4(\mathrm{a})-4(\mathrm{f})$ present SEM images of the mesh samples. Figure 4(a) shows an image of an SS mesh with a Ni underlayer. The surface of the Ni-deposited mesh was uniformly smooth and even. Figures 4(b)-4(f) show SEM images of $\mathrm{Ni} / \mathrm{Sn} / \mathrm{Ni}$ meshes under different $\mathrm{Sn}$ deposition conditions. A whisker structure was observed on the mesh surface after Sn deposition. The length of the whisker structure increased with the Sn deposition current density, except at $300 \mathrm{~mA} \mathrm{~cm}^{-2}$. At an electrodeposition current density of $300 \mathrm{~mA} \mathrm{~cm}^{-2}$, a long whisker structure on the mesh was easily damaged during electrodeposition.

3.4. Simulated Life Cycle Test. The life cycle of the Ni/Sn/Ni mesh, which is used as an OER electrode during the charging cycle in metal-air batteries, was tested in $6 \mathrm{M} \mathrm{KOH}$ solution. The Ni/Sn/Ni mesh was prepared under the aforementioned conditions. A constant current of $1 \mathrm{~mA}$ flowed through the OER electrode/ORR electrode during charging/discharging. Figure 5 shows the cell voltage plotted as a function of the operating time, depicting a relatively stable cell voltage. The cell voltage during charging was approximately $1.55-1.65 \mathrm{~V}$, and that during discharging was approximately $0.85-0.95 \mathrm{~V}$. The life cycle test was terminated after 1,300 cycles. The OER electrode prepared in this study demonstrated stable performance over 1,300 cycles.

\section{Discussion}

4.1. Internal-Resistance-Corrected Tafel Analysis. To determine the main factor responsible for reducing the electrode potential of the $\mathrm{Ni} / \mathrm{Sn} / \mathrm{Ni}$ mesh, the polarization data was 


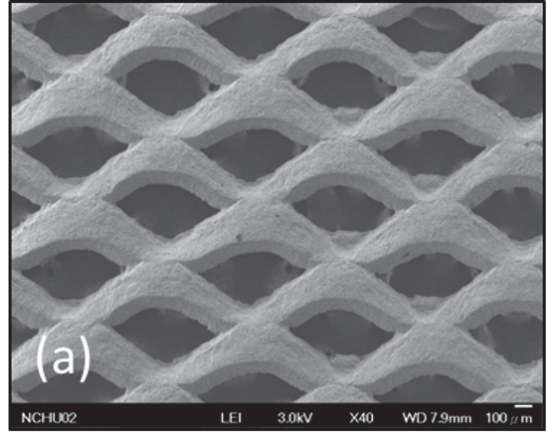

(a)

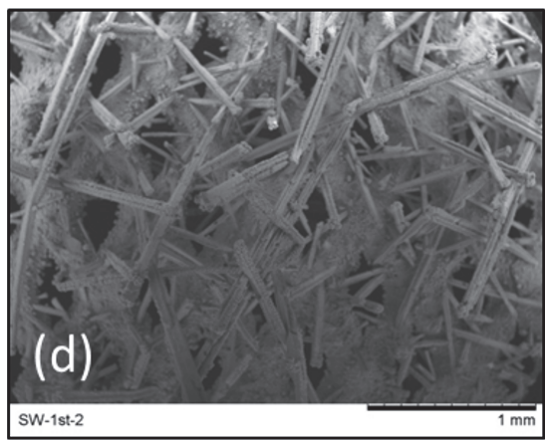

(d)

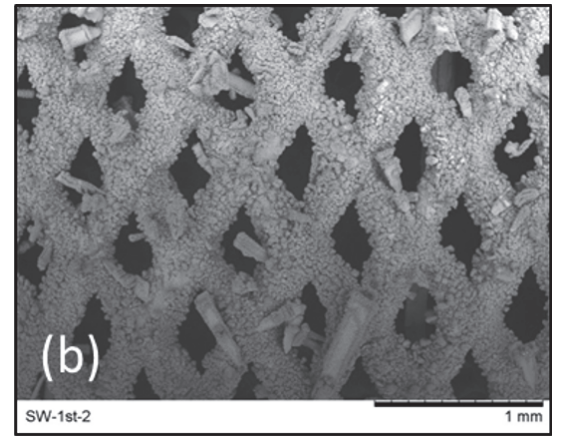

(b)

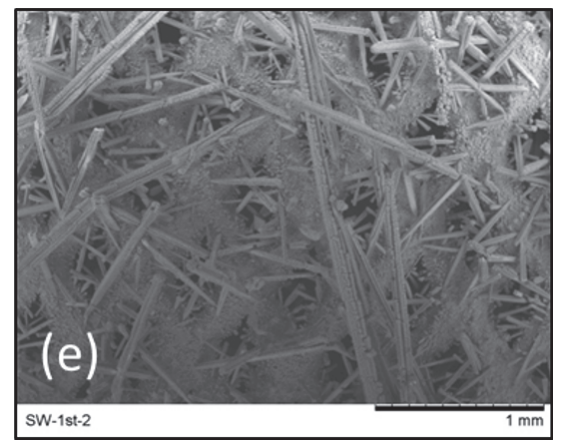

(e)

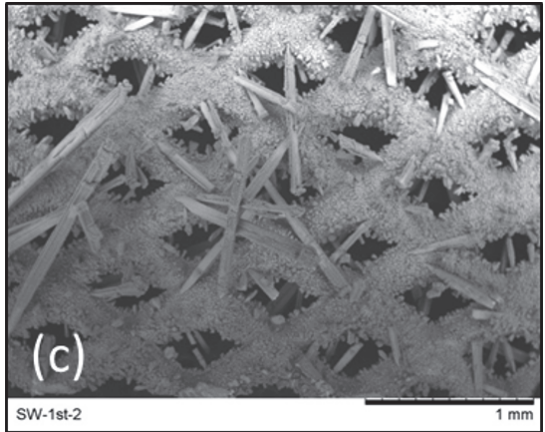

(c)

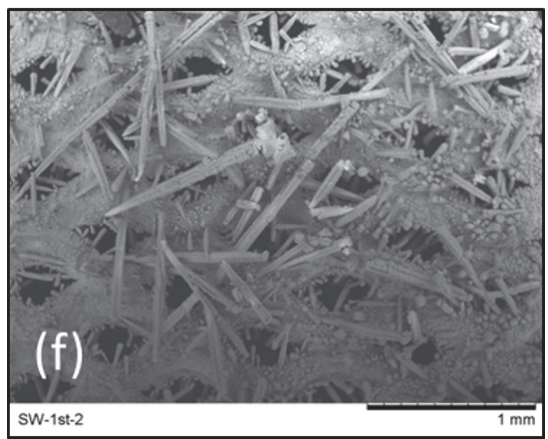

(f)

FIGURE 4: SEM images of Sn electrodeposition on the SS mesh at different electrodeposition currents and for different electrodeposition times: (a) electrodeposition of Ni underlayer; (b) $50 \mathrm{~mA} \mathrm{~cm}^{-2}$ and $500 \mathrm{~s}$; (c) $100 \mathrm{~mA} \mathrm{~cm}^{-2}$ and $250 \mathrm{~s}$; (d) $150 \mathrm{~mA} \mathrm{~cm}^{-2}$ and $166 \mathrm{~s}$; (e) $250 \mathrm{~mA} \mathrm{~cm}^{-2}$ and $100 \mathrm{~s}$; (f) $300 \mathrm{~mA} \mathrm{~cm}^{-2}$ and $83 \mathrm{~s}$.

fitted using the internal resistance- (IR-) corrected Tafel equation.

$$
\varphi=a+b \log i+i R_{\mathrm{ohm}}
$$

where $\varphi$ is the electrode potential, $a$ is the intercept of the Tafel plot, $b$ is the Tafel slope, and $R_{\text {ohm }}$ is the resistance between the working electrode (the mesh) and the reference electrode.

The values of the aforementioned parameters calculated from the regression of the polarization data are plotted in Figure 6. The Tafel slopes and intercepts of the $\mathrm{Ni} / \mathrm{Sn} / \mathrm{Ni}$ meshes corresponding to $\mathrm{Sn}$ electrodeposition at various currents were approximately 0.16 and 0.8 , respectively. The Sn deposition current density exerted little effect on the Tafel intercept and Tafel slope. The results show that the electrode activity exerted little effect on the polarization curve of the OER. The resistance $\left(R_{\mathrm{ohm}}\right)$ decreased with an increase in the $\mathrm{Sn}$ deposition current density, except at $0.3 \mathrm{~A} \mathrm{~cm}^{-2}$ because of a weak whisker structure. The calculated resistances for the data sets obtained at the current densities of 50, 100, 150, 250, and $300 \mathrm{~mA} \mathrm{~cm}^{-2}$ were $3.60,2.97,2.74,2.68$, and $2.98 \Omega \mathrm{cm}^{2}$, respectively. The reduction in the electrode potential of the OER (Figure 6) was mainly because of a decrease in the electrolyte resistance. The removal of gas bubbles led to a decrease in the electrode potential of the OER. The observed gas bubbles were smaller and more uniform in the presence of a whisker structure compared with those in the absence of a whisker structure.

4.2. Double-Layer Charge Capacitance. The whisker structure on an SS mesh provides an additional electrochemically active surface. Applying a high current density for Sn deposition not only increases the number of nucleation sites but also enhances the growth of a large whisker, which tends to inhibit the growth of small whiskers. The influence of the Sn deposition current density on the size of electrochemically active area was investigated.

The relative electrochemically active area on the $\mathrm{Ni} / \mathrm{Sn} / \mathrm{Ni}$ mesh was estimated by measuring the double-layer charging capacitance. The mesh was immersed in $0.5 \mathrm{M} \mathrm{H}_{2} \mathrm{SO}_{4}$ solution, and the electrode potential was scanned between -0.34 and $-0.25 \mathrm{~V}$ versus $\mathrm{AgCl} / \mathrm{Ag}$. In this potential region, no significant Faradaic current was observed, and the current was proportional to the scanning rate. Figure 7 shows a plot of the double-layer charging current as a function of the electrode potential scanning rates $(0.02,0.05,0.1,0.2$, and $0.3 \mathrm{mVs}^{-1}$ ) for different $\mathrm{Sn}$ deposition conditions. The double-layer charging current shows a linear dependence on the electrode potential scanning rate.

The slopes of the lines give the double-layer charge capacitances, and they are plotted against the Sn deposition current density in Figure 8. Clearly, the capacitance increases with the Sn deposition current density for low Sn deposition 


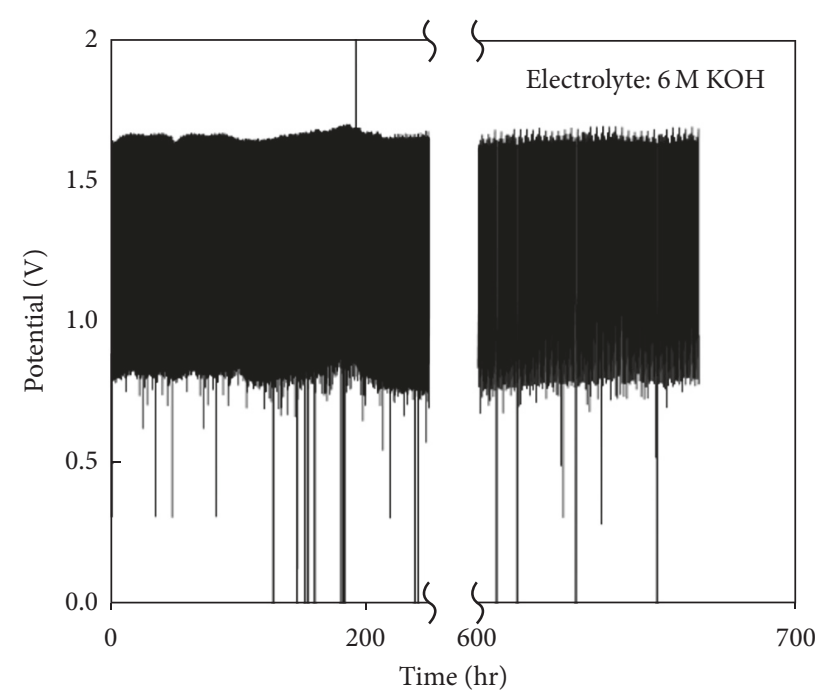

FIGURE 5: Life cycle test for a simulated metal-air battery. The $\mathrm{Ni} / \mathrm{Sn} / \mathrm{Ni}$ mesh was used as the OER electrode during charging. The ORR electrode used was a commercial ORR electrode used in a proton-exchange membrane fuel cell. A Pt wire was used as the metal side electrode. The battery electrolyte was a $6 \mathrm{M} \mathrm{KOH}$ solution. A constant current of $1 \mathrm{~mA}$ flowed through the OER and ORR electrodes during charging and discharging, respectively.

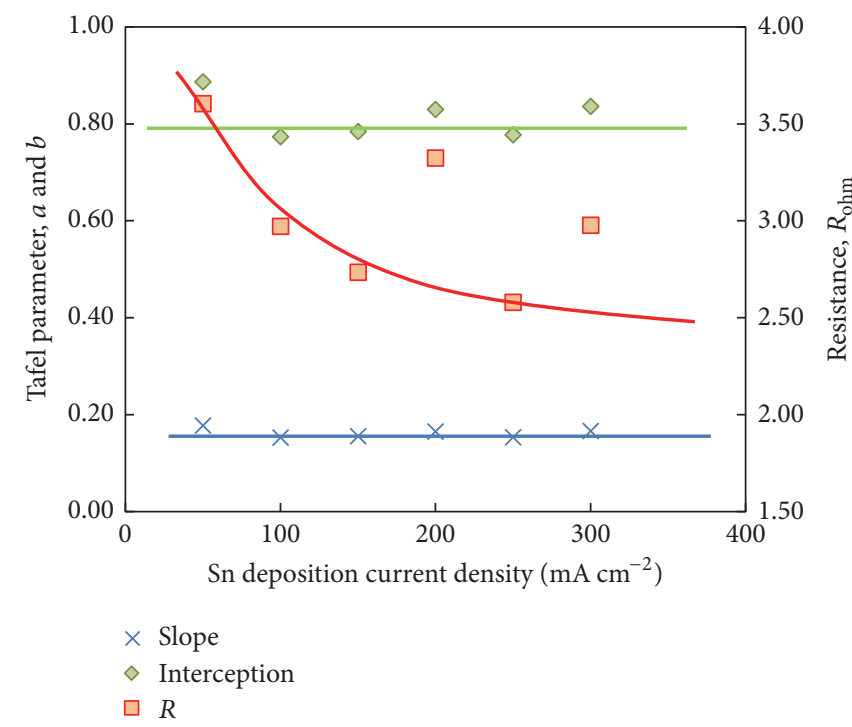

FIgURE 6: Parameters of Tafel regression $\left(a, b\right.$, and $R_{\text {ohm }}$ denote the Tafel slope, Tafel intercept, and resistance, resp.).

current densities $\left(<200 \mathrm{~mA} \mathrm{~cm}^{-2}\right)$. The capacitance decreases with an increase in the Sn deposition current density at high Sn deposition current densities.

\section{Conclusions}

In this study, a whisker structure was formed on the surface of an SS mesh by sequentially depositing a nickel underlayer, a Sn whisker, and a nickel protection layer. SEM images and double-layer charge capacitances indicated that the whisker

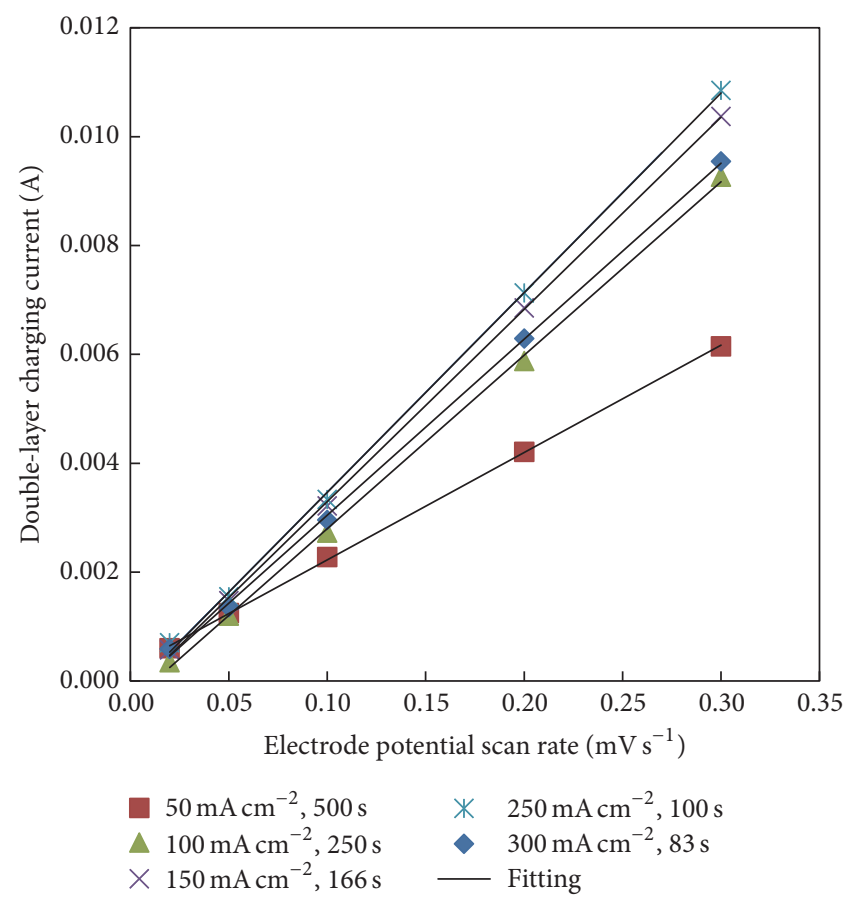

FIGURE 7: Plot of double-layer charging current for $\mathrm{Ni} / \mathrm{Sn} / \mathrm{Ni}$ meshes against $\mathrm{CV}$ scanning rate. The meshes were obtained for different Sn deposition conditions, and they were immersed in $0.5 \mathrm{M} \mathrm{H}_{2} \mathrm{SO}_{4}$ solution.

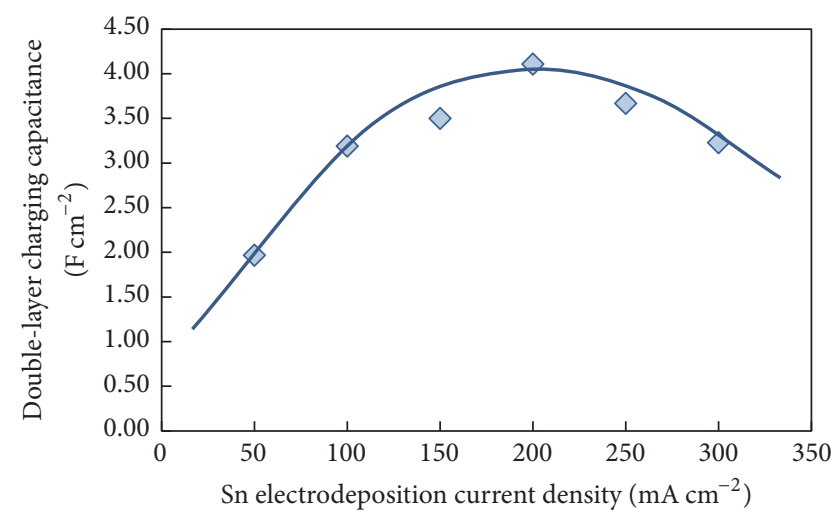

FIGURE 8: Double-layer charge capacitance of Ni/Sn/Ni meshes with $\mathrm{Sn}$ layers deposited at various current densities. The capacitances were calculated from Figure 7.

length and surface area increased with the Sn deposition current density for a constant total charge. High $\mathrm{Sn}$ deposition current densities led to a weak whisker structure because of the formation of a long whisker. The most favorable Sn electrodeposition current density was $0.25 \mathrm{~A} \mathrm{~cm}^{-2}$. Gas bubbles that generated on the $\mathrm{Ni} / \mathrm{Sn} / \mathrm{Ni}$ mesh were small and had a uniform size compared with those on the mesh without any whiskers. The whisker structure on the $\mathrm{Ni} / \mathrm{Sn} / \mathrm{Ni}$ mesh considerably reduced both the IR and overpotential of the OER in $6 \mathrm{M} \mathrm{KOH}$. The life cycle of the mesh reached 1,300 in a simulated charge/discharge cycle test. 


\section{Conflicts of Interest}

The authors declare that they have no conflicts of interest.

\section{Acknowledgments}

This project was conducted under the National Energy Program (NEP) (MOST 106-3113-6-239-001). The authors thank the Ministry of Science and Technology (MOST) for financial support and the Industrial Technology Research Institute/Green Energy and Environment Research Laboratories (ITRI/GEL) for technical support. The authors also thank Li-Xin Chen and Jia-Cing Lyu for their assistance in the experiment.

\section{References}

[1] B. Dunn, H. Kamath, and J.-M. Tarascon, "Electrical energy storage for the grid: a battery of choices," Science, vol. 334, no. 6058, pp. 928-935, 2011.

[2] C.-X. $\mathrm{Zu}$ and H. Li, "Thermodynamic analysis on energy densities of batteries," Energy and Environmental Science, vol. 4, no. 8, pp. 2614-2624, 2011.

[3] M. A. Rahman, X. Wang, and C. Wenz, "High energy density metal-air batteries: a review," Journal of the Electrochemical Society, vol. 160, no. 10, pp. A1759-A1771, 2013.

[4] L. Jörissen, "Bifunctional oxygen/air electrodes," Journal of Power Sources, vol. 155, no. 1, pp. 23-32, 2006.

[5] B. V. Tilak, P. W. T. Lu, J. E. Colman, and S. Srinivasan, "Electrolytic production of hydrogen," in Comprehensive Treatise of Electrochemistry, J. O. M. Bockris, B. E. Conway, E. Yeager, and R. E. White, Eds., vol. 2 of Electrochemical Processing, pp. 1-104, Plenum Press, Berlin, Germany, 1981.

[6] H. M. A. Amin, H. Baltruschat, D. Wittmaier, and K. A. Friedrich, "A highly efficient bifunctional catalyst for alkaline air-electrodes based on a $\mathrm{Ag}$ and $\mathrm{Co} 3 \mathrm{O} 4$ hybrid: RRDE and online DEMS insights," Electrochimica Acta, vol. 151, pp. 332339, 2015.

[7] W. Yan, Z. Yang, W. Bian, and R. Yang, " $\mathrm{FeCo}_{2} \mathrm{O}_{4} /$ hollow graphene spheres hybrid with enhanced electrocatalytic activities for oxygen reduction and oxygen evolution reaction," Carbon, vol. 92, pp. 74-83, 2015.

[8] Y. Li and H. Dai, "Recent advances in Zinc-air batteries," Chemical Society Reviews, vol. 43, no. 15, pp. 5257-5275, 2014.

[9] Z. Chen, A. Yu, R. Ahmed, H. Wang, H. Li, and Z. Chen, "Manganese dioxide nanotube and nitrogen-doped carbon nanotube based composite bifunctional catalyst for rechargeable zinc-air battery," Electrochimica Acta, vol. 69, pp. 295-300, 2012.

[10] M. De Koninck and B. Marsan, "MnxCul-xCo2O4 used as bifunctional electrocatalyst in alkaline medium," Electrochimica Acta, vol. 53, no. 23, pp. 7012-7021, 2008.

[11] Y. Li, M. Gong, Y. Liang et al., "Advanced zinc-air batteries based on high-performance hybrid electrocatalysts," Nature Communications, vol. 4, article 1805, 2013.

[12] C. W. Tobias, "Effect of gas evolution on current distribution and ohmic resistance in electrolyzers," Journal of the Electrochemical Society, vol. 106, no. 9, pp. 833-838, 1959.

[13] M. Philippe, H. Jérôme, B. Sebastien, and P. Gérard, "Modelling and calculation of the current density distribution evolution at vertical gas-evolving electrodes," Electrochimica Acta, vol. 51, no. 6, pp. 1140-1156, 2005.
[14] C. Brussieux, P. Viers, H. Roustan, and M. Rakib, "Controlled electrochemical gas bubble release from electrodes entirely and partially covered with hydrophobic materials," Electrochimica Acta, vol. 56, no. 20, pp. 7194-7201, 2011.

[15] H. Matsushima, T. Iida, and Y. Fukunaka, "Gas bubble evolution on transparent electrode during water electrolysis in a magnetic field," Electrochimica Acta, vol. 100, pp. 261-264, 2013.

[16] R. P. Silva, S. Eugénio, T. M. Silva, M. J. Carmezim, and M. F. Montemor, "Fabrication of three-dimensional dendritic Ni-Co films by electrodeposition on stainless steel substrates," Journal of Physical Chemistry C, vol. 116, no. 42, pp. 22425-22431, 2012.

[17] V. D. Jović, B. M. Jović, and M. G. Pavlović, "Electrodeposition of Ni, Co and Ni-Co alloy powders," Electrochimica Acta, vol. 51, no. 25, pp. 5468-5477, 2006.

[18] X. H. Xia, J. P. Tu, Y. Q. Zhang et al., “Three-dimentional porous nano-Ni/Co(OH)2 nanoflake composite film: a pseudocapacitive material with superior performance," Journal of Physical Chemistry C, vol. 115, no. 45, pp. 22662-22668, 2011.

[19] T. Y. Ma, S. Dai, M. Jaroniec, and S. Z. Qiao, "Metal-organic framework derived hybrid $\mathrm{Co}_{3} \mathrm{O}_{4}$-carbon porous nanowire arrays as reversible oxygen evolution electrodes," Journal of the American Chemical Society, vol. 136, no. 39, pp. 13925-13931, 2014.

[20] W. Ye, J. Yan, Q. Ye, and F. Zhou, "Template-free and direct electrochemical deposition of hierarchical dendritic gold microstructures: growth and their multiple applications," Journal of Physical Chemistry C, vol. 114, no. 37, pp. 15617-15624, 2010.

[21] T. Kakeshita, K. Shimizu, R. Kawanaka, and T. Hasegawa, "Grain size effect of electro-plated tin coatings on whisker growth," Journal of Materials Science, vol. 17, no. 9, pp. 2560$2566,1982$.

[22] W. Zhang and F. Schwager, "Effects of lead on tin whisker elimination," Journal of the Electrochemical Society, vol. 153, no. 5, pp. C337-C343, 2006.

[23] Y.-W. Chiu, S.-H. Chuang, C.-H. Wu et al., "Effects of electrode modification on the air electrode for water electrolysis," ECS Transactions, vol. 58, pp. 9-20, 2014. 

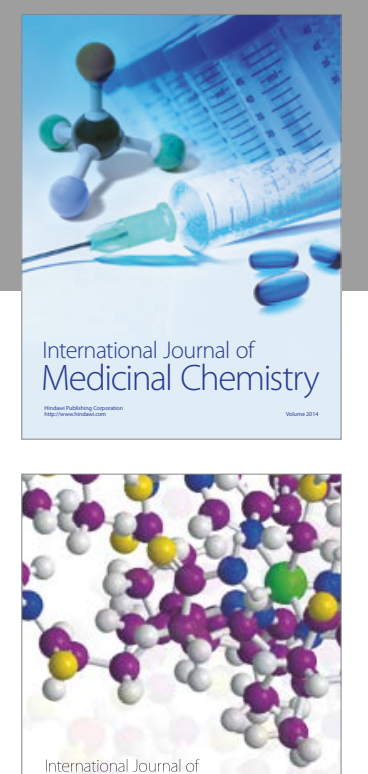

Carbohydrate Chemistry

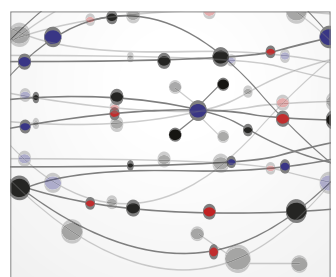

The Scientific World Journal
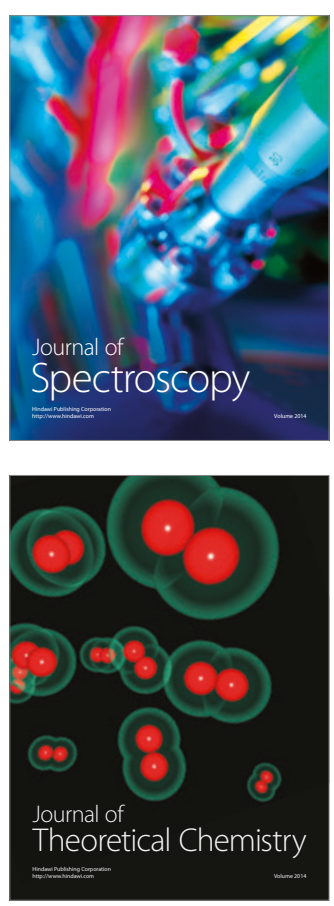
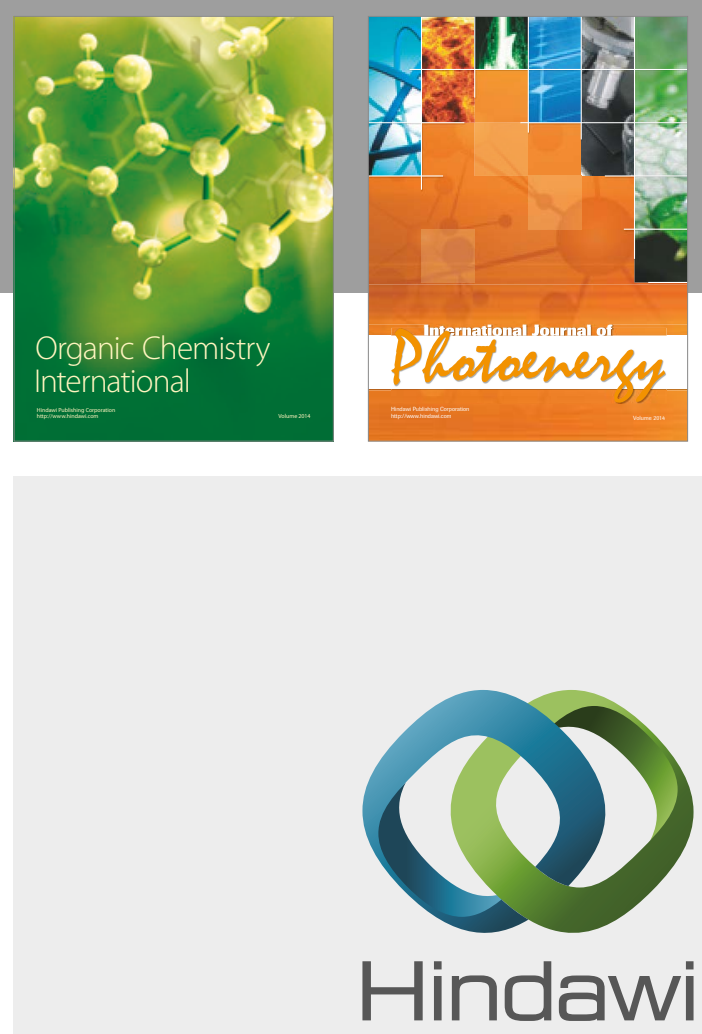

Submit your manuscripts at

https://www.hindawi.com

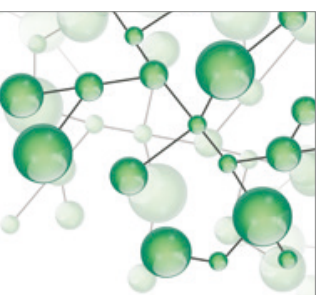

International Journal of

Inorganic Chemistry

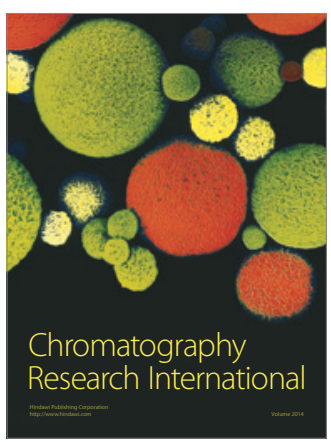

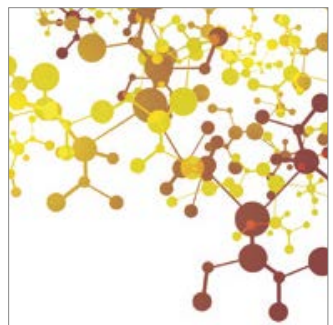

Applied Chemistry
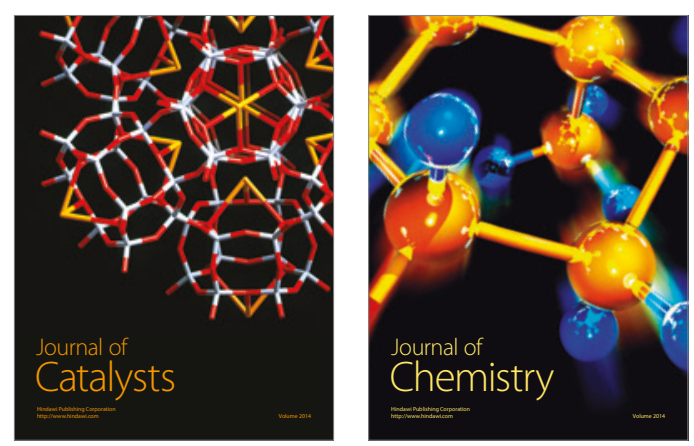
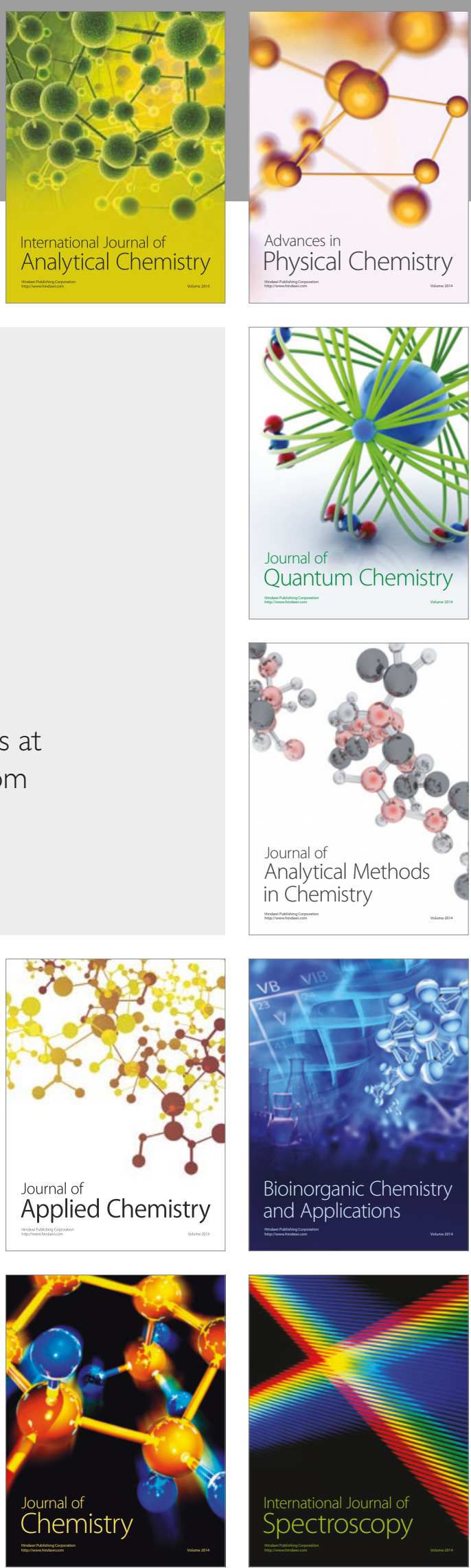